\title{
The Ranschburg effect: The role of guessing strategies
}

\author{
ROBERT L. GREENE \\ Case Western Reserve University, Cleveland, Ohio
}

\begin{abstract}
The Ranschburg effect refers to the finding of impaired serial recall of items repeated on a list. One account attributes this effect to the use of a strategy where subjects avoid using as guesses stimuli that they had recalled elsewhere on the list. Support for this interpretation is reported here. The Ranschburg effect is eliminated when subjects are instructed to avoid guessing. Also, the Ranschburg effect is found in partial report only when subjects are told that the crucial item occurred elsewhere on the list.
\end{abstract}

Immediate serial recall of a list of items is impaired when an item is repeated on a list. This phenomenon, known as the Ranschburg effect, was introduced into the modern memory literature by Crowder and Melton (1965). Two important qualifications are that only recall of the second occurrence of a repeated item is generally impaired and that this effect is typically found only when one or more other items intervene between the two occurrences of a repeated stimulus (Crowder, 1968a). Thus, the Ranschburg effect violates two established principles of memory-namely, that repetition improves memory and that the beneficial effects of repetition improve as a function of spacing.

Two approaches have generally been taken to explain this phenomenon. The first stresses the importance of output interference in memory. This approach claims that the emission of a stimulus as a response somehow makes a second occurrence of that stimulus harder to retrieve. There are several findings supporting the role of output processes. For example, although recall of the second occurrence is impaired when subjects recall a list of items in typical forward fashion, recall of the first occurrence may be impaired when subjects recall a list in backward order (Jahnke, 1969). No Ranschburg effect is found when subjects are given memory tests that do not require emission of an item twice, such as list recognition (Wolf \& Jahnke, 1968) or probed recall of single items (Jahnke, 1970). Also, Ranschburg effects may be caused by response prefixes; when subjects have to emit a stimulus before recall, they are more likely to make errors if that stimulus also occurs on the list (Crowder, 1968b).

A second approach does not deny the importance of output processes in this effect but claims that this is not truly a memory phenomenon at all. Rather, the Ranschburg effect is interpreted as a result of the guessing strategies that a subject follows when he/she is unable to remember

Correspondence concerning this article should be addressed to R. L. Greene, Department of Psychology, Case Western Reserve University, Cleveland, $\mathrm{OH} 44106$ an item (Hinrichs, Mewaldt, \& Redding, 1973). This account assumes that the subject develops guessing strategies to improve his/her recall performance. When the subject gives a stimulus as a response at one point on the list, he/she then avoids using that response as a guess at later positions. ${ }^{1}$ Such a strategy would greatly reduce the chances of getting the second occurrence of a repeated stimulus correctly by chance. Thus, this account explains the Ranschburg effect by assuming that a subject has a much higher probability of guessing an item correctly if that item is not repeated than if it is repeated. It is assumed that, when an item occurs twice at consecutive positions, the subject encodes the fact that there was a repetition on the list and avoids using a no-repetition guessing strategy. This guessing approach is compatible with the evidence reviewed above implicating output processes. Other evidence consistent with this approach is that the Ranschburg effect is not found when probability of correct guessing is reduced by taking list items from a large vocabulary (Hinrichs et al., 1973; Jahnke, 1974) or when subjects know that many lists contain repeated items (Hinrichs \& Mewaldt, 1977). This guessing hypothesis was included in Nairne's (1990) model of immediate memory.

Despite the success of the guessing approach, the basis of the Ranschburg effect is still often considered an open question (e.g., Jahnke \& Bower, 1986), presumably because evidence directly relating guessing to this phenomenon is missing. The only study directly manipulating guessing found inconclusive results. Walsh and Schwartz (1977) gave instructions to their subjects that either encouraged guessing, discouraged guessing, or were neutral. There was no significant difference in the magnitude of the Ranschburg effect in these groups, although there was a slight trend for a larger effect in the group that was encouraged to guess. Walsh and Schwartz interpreted their results as contradicting the guessing account.

The experiments reported here provide support for the guessing account of the Ranschburg effect. Experiment 1 used another form of the instructional manipulation of guessing employed by Walsh and Schwartz (1977). This manipulation was found to have a significant influence 
on the Ranschburg effect. The subsequent experiments studied situations in which the Ranschburg effect may be found even where subjects only have to output one occurrence of the stimulus, thus showing that output interference is not a prerequisite for the appearance of this effect.

\section{EXPERIMENT 1}

Walsh and Schwartz (1977) did not find that guessing instructions significantly influenced the Ranschburg effect. However, one may doubt the conclusiveness of their findings. Two thirds of the lists shown to each subject consisted of word lists drawn from a large vocabulary of possible stimuli. Since only small Ranschburg effects are found with such stimuli (Hinrichs et al., 1973; Jahnke, 1974), there would be less possibility for a significant effect. Moreover, the effect of the instructional manipulation, although small, did go in the direction predicted by the guessing account.

In Experiment 1, the subjects were asked to recall lists of eight digits. The digits 1-9 were used as possible stimuli; the small size of the set of possible stimuli should increase the magnitude of the basic Ranschburg effect. To ensure a sufficient manipulation of guessing, half of the subjects were required to guess, and the remaining subjects were strictly warned against guessing. ${ }^{2}$

\section{Method}

Subjects. Forty-two students from introductory psychology classes participated as subjects to fulfill a course requirement.

Stimuli. Lists of eight digits from the set 1-9 were used as stimuli. A computer generated a different set of 60 test lists for each subject. Stimuli fell into one of five conditions. In the control condition, no item appeared more than once on a list. Two of the conditions were expected to lead to Ranschburg effects. In one of these conditions, a single item occurred at Positions 2 and 5; in the other condition, a digit was repeated at Positions 3 and 6 . (These positions were chosen because they lead to the largest Ranschburg effect; see Crowder, 1968a.) The last two conditions allowed examination of the effects of massed repetitions, which typically enhance immediate serial recall (Crowder, 1968a). In these conditions, digit repetitions occurred at Positions 4 and 5 and at Positions 5 and 6. These positions were chosen so that the position of the second occurrence of a repeated digit would be the same in the two spaced and two massed conditions since the Ranschburg effect is predominantly found at the second occurrence of a spaced repetition.

Procedure. At the beginning of the experiment, the subjects were told that they would be shown lists of eight digits, that digits might occur more than once on a list, and that lists would have to be recalled in order. Half of the subjects (the guessing group) were told that they would always have to make eight responses when recalling each list; if they did not know the digit that occupied a certain position, they would have to guess. The other subjects (the no-guessing group) were told to report only digits they felt confident that they remembered and to avoid guessing.

All lists were presented one digit at a time at a 500 -msec rate on an Apple Ile computer system. The subjects recalled digits by typing them one at a time, pressing the RETURN key after each one. Each response vanished off the screen when the subject pressed RETURN. The no-guessing subjects were told to press RETURN without pressing any digit to indicate a blank response at a certain position. When the subject made his/her eighth response, the next list began after a 2 -sec delay.

Each subject first went through 10 practice lists, half of which had no repetitions and the other half of which had repeated digits at positions other than $2,4,5$, and $6 .^{3}$ The subjects then went through the 60 test lists. The five conditions were randomly mixed, with the computer generating a different random order of the conditions for each subject.

\section{Results and Discussion}

All analyses used a .05 significance level. The results are shown in Table 1. Because stimuli came from a small vocabulary, each response was scored correct only if it occupied the correct position. The first question to ask is whether a typical Ranschburg effect was found. This can be determined by looking at the critical experimental positions (Position 5 on the 2-5 lists and Position 6 on the 3-6 lists) and comparing them with Positions 5 and 6 on the control lists. In the guessing condition, there was a large difference between the control and experimental conditions at these positions. In the no-guessing condition, this difference was greatly reduced. This conclusion was tested statistically by forming a Ranschburg score made up of the sum of the items recalled at Position 5 in the 2-5 condition and at Position 6 in the 3-6 condition. This score was compared with a control score (sum of the items recalled from Positions 5 and 6 in the control condition). There was a significant overall difference between the Ranschburg and control scores $\left[F(1,40)=9.83, M S_{e}=7.37\right]$. The main effect of instructional group was not significant $(F<1)$, but there was a significant interaction between group and condition $\left[F(1,40)=6.62, M S_{\mathrm{e}}=7.37\right]$. Subsequent analyses revealed a significant difference between the Ranschburg and control scores in the guessing group $[F(1,20)=$ $\left.14.87, M S_{e}=8.07\right]$, but not in the no-guessing group $\left[F(1,20)=0.18, M S_{\mathrm{e}}=6.67\right]$.

It should be noted that the interaction between condition and instructional group followed the pattern that would be predicted by the guessing account of Ranschburg effects. No-guessing instructions lowered recall in the control condition because they reduced the possibil-

Table 1

Proportions of Items Recalled in Experiment 1

\begin{tabular}{|c|c|c|c|c|c|c|c|c|}
\hline \multirow[b]{2}{*}{ List Type } & \multicolumn{8}{|c|}{ Serial Position } \\
\hline & 1 & 2 & 3 & 4 & 5 & 6 & 7 & 8 \\
\hline \multicolumn{9}{|c|}{ Guessing Group } \\
\hline Control & .90 & .79 & .75 & .63 & .50 & .45 & .47 & .58 \\
\hline $2-5$ & .88 & .78 & .73 & .65 & .39 & .42 & .43 & .56 \\
\hline $3-6$ & .89 & .79 & .71 & .60 & .50 & .33 & .40 & .55 \\
\hline $4-5$ & .90 & .82 & .77 & .77 & .72 & .47 & .44 & .57 \\
\hline $5-6$ & .92 & .82 & .76 & .68 & .69 & .70 & .46 & .54 \\
\hline \multicolumn{9}{|c|}{ No-Guessing Group } \\
\hline Control & .86 & .70 & .69 & .60 & .42 & .37 & .33 & .50 \\
\hline $2-5$ & .92 & .73 & .68 & .61 & .40 & .36 & .37 & .51 \\
\hline $3-6$ & .87 & .72 & .64 & .59 & .45 & .35 & .33 & .50 \\
\hline $4-5$ & .91 & .77 & .68 & .71 & .70 & .41 & .33 & .53 \\
\hline $5-6$ & .90 & .76 & .70 & .63 & .68 & .64 & .42 & .53 \\
\hline
\end{tabular}


ity that the subjects would get an item correct by guessing. However, the instructions had little effect on the critical Ranschburg positions (Position 5 on the 2-5 lists and Position 6 on the 3-6 lists). Because subjects avoid using previous responses as guesses, they had little chance of guessing these items correctly anyway. Thus, whether or not subjects guess has little impact on the probability of a correct response at these positions.

A similar approach can be taken to the effects of massed repetitions. According to the guessing account of Ranschburg effects (Hinrichs et al., 1973), subjects only refrain from guessing repeated digits when they have not specifically encoded the fact of a repetition while seeing the list. Because items repeated at consecutive positions are likely to be encoded as a unit (Lee, 1976), massed repetitions should not be affected by guessing instructions. A massed score was made for each subject by adding the number of items recalled at Position 5 in the 4-5 lists and at Position 6 in the 5-6 lists. The difference between the massed score and the control score was significant $\left[F(1,40)=62.44, M S_{\mathrm{e}}=14.10\right] ;$ this difference did not interact significantly with the instructional group $(F<1)$.

The results of Experiment 1 were entirely consistent with predictions made by a guessing account. There was a significant Ranschburg effect (an inhibition in recall of the second occurrence of a spaced repetition), but this effect was eliminated when the subjects were told to refrain from guessing. Massed repetitions significantly improved recall, and this effect was not influenced by guessing instructions.

\section{EXPERIMENT 2}

One of the strongest generalizations that can be made about the Ranschburg effect is that it has been shown to be a result of a subject's having to emit the same response twice. As mentioned above, this effect is not found when subjects do not have to make the same response twice. For example, when subjects are given probed-recall tests of individual items, no Ranschburg effect is found (Jahnke, 1970).

According to guessing accounts, it is not output interference that is involved. Rather, it is the subjects' knowledge that a stimulus had occurred earlier on the list that makes them hesitate to use that same stimulus as a guess. Thus, one should be able to find Ranschburg effects even when only one occurrence of a stimulus has to be reported, as long as subjects know that the stimulus did occur elsewhere on the list.

This was accomplished in Experiment $2 \mathrm{~A}$ by requiring only recall of the second half of the list on some trials. On those trials, the subjects would be given the first four items and would have to recall the last four. Repetitions would either be spaced (at Positions 2 and 5) or massed (at Positions 4 and 5). Because subjects know that an item occurred in the first half of the list on these trials, they should refrain from guessing that stimulus in the second half, which should lead to a Ranschburg effect when repe- titions were spaced. Since subjects are more likely to encode the fact that a stimulus was repeated when massed repetitions occur, guessing should not play any role there.

\section{Experiment 2A}

\section{Method}

Subjects. Twenty-two students from introductory psychology classes participated as subjects to fulfill a course requirement.

Stimuli. Each subject again received 10 practice and 60 test lists of eight digits, all of which were computer-generated individually for each subject. Of the 60 test lists, 20 had no repeated items, 20 included a repeated digit at Positions 2 and 5, and 20 included a repeated digit at Positions 4 and 5 . Of the 10 practice lists, 5 had no repetitions and 5 had repetitions at positions other than 2,4 , and 5 .

Procedure. As in Experiment 1, lists were presented on a computer screen at a $500-\mathrm{msec}$ rate. On half of the trials, the subject recalled all eight items. The other trials were partial-recall trials. On these trials, the computer printed the first four items on the screen. The subject recalled the next four items, with each response vanishing after the subject pressed the RETURN key. The first four items stayed on the screen until the last item was recalled. All subjects were required to make a response for every position, as in the guessing condition in Experiment 1. Full- and partial-recall trials were randomly mixed, as were control, 2-5 repetition, and 4-5 repetition lists. Practice trials contained equal numbers of full- and partial-recall trials.

\section{Results and Discussion}

The results are shown in Table 2 . When one examines the full-report condition, it is clear that the standard findings were obtained. There was a Ranschburg effect, with recall of the fifth item on the 2-5 lists being significantly lower than recall of the fifth item on the control lists $\left[F(1,21)=25.44, M S_{\mathrm{e}}=2.70\right]$. This was the only position for which there was a significant difference between

Table 2

Proportions of Items Recalled in Experiments 2A, 2B, and 3

\begin{tabular}{|c|c|c|c|c|c|c|c|c|c|}
\hline \multirow{2}{*}{$\begin{array}{c}\text { Recall } \\
\text { Condition }\end{array}$} & \multirow[b]{2}{*}{ List Type } & \multicolumn{8}{|c|}{ Serial Position } \\
\hline & & 1 & 2 & 3 & 4 & 5 & 6 & 7 & 8 \\
\hline \multicolumn{10}{|c|}{ Experiment $2 \mathrm{~A}$} \\
\hline \multirow[t]{3}{*}{ Full } & Control & .89 & .80 & .71 & .68 & .64 & .54 & .53 & .64 \\
\hline & $2-5$ & .90 & .74 & .69 & .65 & .39 & .43 & .43 & .60 \\
\hline & $4-5$ & .85 & .77 & .72 & .76 & .77 & .50 & .45 & .61 \\
\hline \multirow[t]{3}{*}{ Partial } & Control & - & - & - & - & .76 & .73 & .68 & .79 \\
\hline & $2-5$ & - & - & - & - & .58 & .64 & .60 & .75 \\
\hline & $4-5$ & - & - & - & - & .89 & .77 & .69 & .77 \\
\hline \multicolumn{10}{|c|}{ Experiment 2B } \\
\hline \multirow[t]{3}{*}{ Full } & Control & .86 & .75 & .62 & .57 & .55 & .40 & .38 & .55 \\
\hline & $2-5$ & .91 & .61 & .64 & .58 & .37 & .40 & .38 & .49 \\
\hline & $4-5$ & .86 & .67 & .59 & .72 & .74 & .41 & .38 & .51 \\
\hline \multirow[t]{3}{*}{ Partial } & Control & - & - & - & - & .59 & .56 & .54 & .73 \\
\hline & $2-5$ & - & - & - & - & .58 & .57 & .54 & .71 \\
\hline & $4-5$ & - & - & - & - & .83 & .60 & .59 & .73 \\
\hline \multicolumn{10}{|c|}{ Experiment 3} \\
\hline \multirow[t]{3}{*}{ Full } & Control & .94 & .80 & .75 & .68 & .63 & .46 & .35 & .55 \\
\hline & $2-5$ & .94 & .79 & .74 & .69 & .47 & .40 & .28 & .49 \\
\hline & $4-5$ & .89 & .85 & .80 & .89 & .73 & .38 & .36 & .51 \\
\hline \multirow[t]{3}{*}{ Partial } & Control & .92 & .83 & .77 & .76 & - & - & - & - \\
\hline & $2-5$ & .96 & .67 & .74 & .70 & - & - & - & - \\
\hline & $4-5$ & .91 & .83 & .78 & .84 & - & - & - & - \\
\hline
\end{tabular}


the 2-5 and control lists. As expected, massed repetition had the opposite effect: Recall of the fifth item on the 4-5 lists was significantly higher than recall of the fifth item on the control lists $\left[F(1,21)=6.36, M S_{e}=3.22\right]$.

The crucial findings are in the partial-recall data. The central finding is that partial recall showed the same pattern as full recall. There was a significant Ranschburg effect, with recall of the fifth item on the 2-5 lists being significantly lower than recall of the fifth item on the control lists $\left[F(1,21)=9.73, M S_{e}=2.70\right]$. In addition, recall of the fifth item was significantly higher for the 4-5 lists than for the control lists $\left[F(1,21)=7.46, M S_{e}=2.74\right]$.

The Ranschburg effect was found in partial recall even though the subjects were only tested for one of the two occurrences. This finding runs counter to previous findings of Ranschburg effects only when subjects had to emit both occurrences (Jahnke, 1970; Wolf \& Jahnke, 1968). This conflict can be explained by the guessing hypothesis. In Experiment 2A, on partial-recall lists, the first four items were given to the subjects, thereby allowing them to avoid using those items as guesses. This was not done in previous studies. Admittedly, however, the procedure used in Experiment 2A was not particularly similar to those used in previous studies, so an additional experiment (Experiment 2B) was later conducted to ensure that it was the fact that the subjects were given the first four items that led to the presence of a Ranschburg effect.

\section{Experiment 2B}

In Experiment 2B, 19 subjects from the same source were tested. The procedure was identical to that used in Experiment 2A, with the exception that, on partial-recall trials, the subjects were not given the first four items. Instead, four Xs appeared on the screen to indicate that only the last four items had to be recalled. The results are given in Table 2. On full-recall trials, recall at Position 5 was significantly higher for the control lists than for the 2-5 lists $\left[F(1,18)=15.71, M S_{\mathrm{e}}=1.82\right]$ and higher for the 4-5 lists than for the control lists $[F(1,18)=18.49$, $\left.M S_{\mathrm{e}}=2.06\right]$. On the partial-recall trials, there was no difference in recall of the fifth item between the control and the 2-5 lists $\left[F(1,18)=0.07, M S_{\mathrm{e}}=1.49\right]$. In other words, there is no Ranschburg effect in partial recall unless the experimenter shows the subject the other items. There was still an advantage at Position 5 for the 4-5 lists over control lists $\left[F(1,18)=12.18, M S_{\mathrm{e}}=4.57\right]$

\section{EXPERIMENT 3}

The Ranschburg effect is typically found only at the second occurrence of a repeated item. However, if subjects are required to recall items in reverse order, recall is impaired for the first occurrence, and not for the second occurrence, of the repeated item (Jahnke, 1969). This finding suggests that a Ranschburg effect may be found at the first occurrence of a repeated item in a partial-recall task if subjects are given the last four items and are asked to recall the first four items.

\section{Method}

Subjects. Twenty students from introductory psychology classes participated as subjects to fulfill a course requirement.

Procedure. The conditions, stimuli, and procedure were identical to those used in Experiment 2A, with the exception that, on partial-recall trials, the subjects were shown the last four items on the screen and were required to recall the first four items.

\section{Results and Discussion}

The results are shown in Table 2. The crucial comparison here is in the partial-recall data between the control and the 2-5 lists. Note that, in partial recall, there was a substantial decrement at Position 2 for the 2-5 lists, relative to control lists $\left[F(1,19)=9.65, M S_{\mathrm{e}}=2.65\right]$. Knowing that an item occurred later in the list made the subjects less likely to emit that item in partial recall. This finding is consistent with the guessing account of the Ranschburg effect.

For the sake of completeness, it should be noted that the full-recall data exhibit the same patterns as were found previously. The standard Ranschburg effect was present, as shown by the fact that recall of the fifth item was higher on the control lists than on the 2-5 lists $[F(1,19)=19.93$, $\left.M S_{\mathrm{e}}=1.28\right]$. This effect was only present at the second occurrence of repeated items. There was no difference in recall of the second item between the control and the $2-5$ lists $\left[F(1,19)=0.47, M S_{\mathrm{e}}=2.57\right]$. Massed repetitions again facilitated recall, as exhibited by the significant advantage at Position 5 for the 4-5 lists over control lists $\left[F(1,19)=7.60, M S_{e}=1.32\right] .^{4}$

\section{GENERAL DISCUSSION}

The guessing hypothesis was supported in these experiments as an explanation for the Ranschburg effect. The effect was eliminated when the subjects were told to avoid guessing (Experiment 1). Also, the effect appeared in partial recall of the last four items when the subjects were given the first four items (Experiment 2A) and in partial recall of the first four items when the subjects were given the last four items (Experiment 3).

The Ranschburg effect first appeared as a paradoxical phenomenon that violates the well-established principles that repetition improves memory and that spaced repetitions are more beneficial than are massed repetitions. According to the guessing hypothesis, however, this paradox is more apparent than real. The basic effect is seen as not reflecting memory at all. Rather, it is attributed to guessing strategies that subjects follow when they do not remember the item that occupied a particular location. This does not imply that memory plays no role here. Subjects adopt this no-repetition guessing strategy only when they do not remember the fact that a list contained repetitions. Since subjects are far more likely to detect repetitions when they are massed than when they are spaced (Lee, 1976), this strategy is applied chiefly when repetitions are spaced.

Recently, several phenomena have been interpreted as reflecting biases subjects follow when guessing, such as 
interference in eyewitness testimony (McCloskey \& Zaragoza, 1985) and some systematic errors in time estimation (Huttenlocher, Hedges, \& Bradburn, 1990). The Ranschburg effect appears to be another memory phenomenon reflecting guessing strategies. It has become increasingly clear that, in order to have an adequate explanation of performance on memory tests, we need to understand how people respond when they are not able to remember.

\section{REFERENCES}

Crowder, R. G. (1968a). Intraserial repetition effects in immediate memory. Joumal of Verbal Learning \& Verbal Behavior, 7, 446-451.

Crowder, R. G. (1968b). Repetition effects in immediate memory when there are no repeated elements in the stimuli. Journal of Experimental Psychology, 78, 605-609.

Crowder, R. G., Melton, A. W. (1965). The Ranschburg phenomenon: Failures of immediate recall correlated with repetition of elements within a stimulus. Psychonomic Science, 2, 295-296.

Hinrichs, J. V., \& Mewaldi, S. P. (1977). The Ranschburg effect: Modification of guessing strategies by context. Bulletin of the Psychonomic Society, 9, 85-88.

Hinrichs, J. V., Mewaldt, S. P., \& Redding, J. (1973). The Ranschburg effect: Repetition and guessing factors in short-term memory. Journal of Verbal Learning \& Verbal Behavior, 12, 64-75.

Huttenlocher, J., Hedges, L. V., \& Bradburn, N. M. (1990) Reports of elapsed time: Bounding and rounding processes in estimation. Journal of Experimental Psychology: Learning, Memory, \& Cognition, 16, 196-213.

JAHNKE, J. C. (1969). Output interference and the Ranschburg effect Journal of Verbal Learning \& Verbal Behavior, 8, 614-621.

JAHNKE, J. C. (1970). Probed recall of strings that contain repeated elements. Journal of Verbal Learning \& Verbal Behavior, 9, 450-455.

JAHNKE, J. C. (1974). Restrictions on the Ranschburg effect. Journal of Experimental Psychology, 103, 183-185.

JAHNKE, J. C., \& Bower, R. E. (1986). Are there two Ranschburg effects? American Journal of Psychology, 99, 275-288.

LEE, C. L. (1976). Short-term recall of repeated items and detection of repetitions in letter sequences. Joumal of Experimental Psychology: Human Learning \& Memory, 2, 120-127.

McCloskey, M., Zaragoza, M. (1985). Misleading postevent information and memory for events: Arguments and evidence against memory impairment hypotheses. Journal of Experimental Psychology: General, 114, 381-387.

NaIRNE, J. S. (1990). A feature model of immediate memory. Memory \& Cognition, 18, 251-269.

WALSh, M. F., SCHWARTZ, M. (1977). The Ranschburg effect: Tests of the guessing-bias and proactive interference hypotheses. Journal of Verbal Learning \& Verbal Behavior, 16, 55-68.

Wolf, T. M., JAHNKE, J. C. (1968). The effects of intraserial repetition on short-term recognition and recall. Joumal of Experimental Psychology, 77, 572-580.

\section{NOTES}

1. The guessing account is often phrased as if all responses are based on either memory or guesses. This need not be true, however. One could choose to think of this approach as simply saying that subjects raise their response criterion if the potential response had already been emitted.

2 . There was no group given neutral instructions regarding guessing, largely because it was not clear how such instructions could be implemented given the procedure used here. Walsh and Schwartz (1977) did use a neutral-instructions group and found that this group fell into an intermediate position between the guessing and the no-guessing groups.

3. The purpose of including practice lists with repetition patterns different from those used on test lists was to prevent the subjects from realizing that repeated items could only occur at a few positions. This was effective. Postexperiment debriefings found that none of the subjects in any of the present experiments could accurately describe the pattern of repetitions used on test lists.

4. It is perhaps worth noting that, in all of the partial-recall conditions in Experiments 2A, 2B, and 3, the subjects rarely made an error by recalling an item that they were told occurred in the other half of the list. (In each condition, the percentage of error responses that were repetitions of stimuli from the unrecalled half was less than 10\%; random chance would lead to a percentage of $44 \%$.) Thus, the subjects did seem to avoid making repetitions when they were guessing. Also, in all of the conditions in Experiments 1, 2A, 2B, and 3, the subjects rarely repeated a number in output that had not been repeated on the list; on fewer than $10 \%$ of the lists, in all conditions, did subjects claim that a number occurred twice on a list when it had been presented no more than once.

(Manuscript received July 20, 1990; revision accepted for publication November $5,1990$. ) 